\title{
ESPERANÇAS DO PASSADO
}

\section{Luiz Gonzaga Belluzo}

"Nós somos herdeiros, o que não quer dizer que possuímos ou recebemos isto ou aquilo, ou que possamos enriquecer com a herança. Mas o ser daquilo que somos é já, em seu começo, uma herança. Não importa se nós a desejamos, saibamos dela ou não. Hölderlin considerava a linguagem o mais perigoso dos bens. Mas ela foi entregue ao homem para que ele dê o testemunho de haver herdado o que ele é. A herança jamais é uma doação, mas uma tarefa.” (Jacques Derrida - Spectres de Marx)

Sou um filho do mundo que nasce no pós-guerra, da São Paulo da Ciranda de Pedra, de nossa querida Lígia Fagundes Telles e do Brasil que arfava entre a euforia da vitória das democracias e as esperanças do desenvolvimentismo.

Já antes do término da Segunda Guerra Mundial, o projeto hegemônico dos vencedores, os Estados Unidos, foi

1. Texto baseado no discurso em que o autor recebeu o Prêmio Juca Pato - Intelectual do Ano de 2005, da União Brasileira dos Escritores. 
desenhado com o propósito de eliminar os fatores políticos e econômicos que levaram às duas conflagrações globais. A instabilidade econômica e as rivalidades interimperialistas - entre o final do século XIX e a Segunda Guerra Mundial - foram devastadoras do ponto de vista econômico, social, moral e político. Terminado o conflito, as forças vitoriosas, democráticas e antifascistas, trataram de criar instituições destinadas a impedir a repetição da desordem destrutiva que nascera da rivalidade entre as potências e da economia destravada.

Só o maniqueísmo típico da Guerra Fria se atreveria a negar que as forças sociais e o imaginário político predominantes no New Deal tinham uma visão progressista acerca do papel a ser exercido pelos Estados Unidos. Em claro antagonismo com as práticas das velhas potências, os Estados Unidos - tomando em conta o seu auto-interesse de forma esclarecida - se empenharam na reconstrução européia e 58 apoiaram as lutas pela descolonização.

O que se observou, a partir de então, foi um ensaio apenas um ensaio - de uma nova ordem internacional com aspirações de garantir os direitos do homem e do cidadão, os princípios da democracia e da legalidade internacional. Isto ocorreu, é verdade, num ambiente de tensão permanente entre as duas superpotências e de competição entre os seus sistemas de vida. Ao mesmo tempo, cresciam a interdependência e a rivalidade econômica entre a Europa ocidental, os Estados Unidos e o Japão, assim como se aceleraram os processos de desenvolvimento em meio à sucessão de crises políticas e golpes de Estado na periferia.

O desenvolvimentismo - é preciso que se diga com ênfase - não foi uma invenção idiossincrática de países exóticos. Foi, antes de tudo, uma resposta aos desafios e oportunidades criadas pela Grande Depressão dos anos 30 e seu ambiente internacional catastrófico. Os projetos nacionais de desenvolvimento e industrialização na periferia nasce- 
ram no mesmo berço que produziu o keynesianismo nos países centrais. Uma reação contra as misérias e as desgraças produzidas pelo capitalismo dos anos 20.

A onda desenvolvimentista e a experiência keynesiana tiveram o seu apogeu nas três décadas que sucederam o fim da Segunda Guerra. O clima político e social estava saturado da idéia de que era possível adotar estratégias nacionais e internacionais de crescimento, industrialização e avanço social.

Depois de trinta anos de progresso material, redução das desigualdades nos países centrais e altas taxas de crescimento na América Latina e na Ásia emergente, a crise dos anos 70 foi entendida como uma advertência e uma recomendação: era preciso dar adeus a tudo aquilo. O mal é a política. O intervencionismo do Estado, o poder dos sindicatos, o controle público da finança, os obstáculos ao livre movimento de capitais.

O conto de fadas da globalização acenava com o fim da história: as questões essenciais relativas às formas de convivência e ao regime de produção em escala mundial estariam resolvidas com a generalização da democracia liberal e da economia de mercado. Não haveria mais sentido na discussão de questões anacrônicas, como as da pertinência cívica, laica e republicana, sentimento desenvolvido a partir do nascimento do Estado-Nação e consolidado com o Estado do Bem-Estar Social.

Um jornalista do Guardian, habitual cronista das reuniões do World Economic Forum, resumiu em um parágrafo as diferenças entre o espírito das épocas, entre as reuniões de Bretton Woods e Durbaton Oaks e os encontros periódicos de Davos, onde os poderes do mundo imaginam cuidar do destino dos homens: "Clement Atlee, Ernest Bevin e Roosevelt acreditavam nos mercados administrados e no controle do capitalismo... por isso as Conferências de Bretton Woods e de Durbaton Oaks não foram patrocinadas pela Coca-Cola. As reuniões de Roosevelt não tinham o apoio do J. P. Morgan, 
cujos funcionários, aliás, tratavam de recortar as fotos do presidente americano, para evitar acidentes, caso o patrão resolvesse ler os jornais."

O sonho do fim da história e da cidadania sem fronteiras transformou-se no pesadelo em que todos são vítimas prováveis do embate entre o desespero dos que não têm rosto - porque não têm pátria - e uma estrutura de poder global que se pretende absoluta, encarnada no rosto da pátria hegemônica.

A dominação pós-moderna pretende desconhecer a soberania dos estados nacionais, sem que isso signifique a criação de instâncias integradoras no âmbito internacional. Muito ao contrário: o avanço do intervencionismo unilateral provoca a desintegração dos fóruns multilaterais. A política norte-americana faz unilateralmente as "intervenções preventivas" ou "corretivas", segundo a conjuntura. Sem regras gerais auto-aplicáveis e sem consideração pelas regras 60 dos organismos internacionais que eles mesmos ajudaram a criar, o "intervencionismo preventivo" norte-americano expandiu como nunca o seu poder global.

A supremacia apoiada na superioridade das armas e no despotismo da economia desregulada dispensa as mediações da ordem jurídica e não quer ou não precisa compreender nada. A busca humana e libertadora da compreensão tende a esmaecer quando prevalece a "lógica da cacetada". A estratégia de Bush e da nova direita fundamentalista, segundo o filósofo Slavo Zizek, é bloquear as possibilidades libertadoras da sociedade americana: "Não estou dizendo que Bush vai usar o pretexto da ameaça terrorista para instaurar uma meia ditadura militar. Não! Isso será feito de forma imperceptível, mediante regras não escritas. Alguém poderia imaginar a tortura como um tópico legítimo três ou quatro anos atrás? Minha maior preocupação é esta revolução suave, essa imperceptível mudança nas normas sociais, nas regras não escritas sobre o que é aceitável ou não.” 
É impossível não temer que Adorno e Horkheimer tivessem razões para sustentar a terrível suspeita: o mundo em que tentamos sobreviver é uma prova diária da degeneração da razão ocidental, transformada em mero instrumento dos métodos de domínio e conquista. Não vejo como a razão instrumental e tecnocrática, encarnada na economia - esta obra-prima do que há de pior na metafísica ocidental - possa empreender a crítica de sua própria grande narrativa.

O implacável crítico inglês Terry Eagleton descreve o atual estado de coisas no mundo como um processo em que a diferenciação de atitudes, estilos, modos de ser e de governar são tão semelhantes entre si que, afinal de contas, não há qualquer diferença entre eles. Eagleton constata que, no capitalismo globalizado, as leis de movimento do conjunto vão se tornando mais abstratas e constrangedoras e, ao mesmo tempo, as pretensões particularistas e individualistas tornam-se grotescamente infladas, ameaçando lançar a sociedade na violência e no caos.

As lideranças "renovadas" da periferia, por exemplo, tiveram os seus dias de glória. Hoje o que vemos são cadáveres boiando na enxurrada da globalização. Quanto mais crédula a adesão às torrentes da mercantilização universal, mais rasa a poça d'água em que terminam por se afogar os clones de estadistas.

Os governantes, auto-intitulados progressistas - acuados pelos favores da alta finança - tratam de cortar os direitos sociais e econômicos de seus cidadãos enquanto celebram a eficiência dos mercados. Sob o pretexto de enfrentar o corporativismo e a resistência dos "direitos adquiridos", os serviçais da globalização propõem o retorno aos padrões primitivos nas relações entre o capital e o trabalho. Não satisfeitos, advogam o encolhimento do sistema de proteção social criado para impedir a desgraça dos mais fracos, o sofrimento do homem comum atormentado, dia sim, dia não, pelas peripécias dos mercados. 
Esses são os princípios que vêm conduzindo as "reformas", tanto as dos países desenvolvidos quanto as mimetizadas por governantes de países periféricos. Julgam, com estes programas, estar comprando o ingresso para o clube dos ricos. Estão, na verdade, trocando a saúde, a educação do povo e o sossego dos velhos por miragens.

Ao se pronunciar sobre a experiência do período desenvolvimentista, um ex-presidente do Banco Central chegou a proclamar - em entrevista à revista Veja - que aqueles tempos foram "40 anos de burrice". Assim prolatada esta irrecorrível sentença condenatória reverbera a pobreza da teoria econômica dominante, que, já disse, se transformou na filha mais dileta e degenerada da metafísica ocidental, no seu pressuroso anseio de eliminar as diferenças no modo de ser e de existir dos países e dos cidadãos.

Era, então, arriscado - para não dizer quase proibido - apenas sugerir que o prolongado desfile de "burrice", afi62 nal, livrou o Brasil e os brasileiros da dependência do modelo primário-exportador (além do bicho-de-pé e da hemoptise) e forjou uma importante economia urbana e industrial no chamado Terceiro Mundo.

O ethos desenvolvimentista foi construído pela interação entre as camadas empresariais nascentes, o estamento burocrático-militar e algumas lideranças intelectuais e o proletariado em formação. Havia a percepção de que o objetivo de aproximar o país das formas de produção e de convivência não poderia ser alcançado no âmbito da velha e destroçada divisão internacional do trabalho e nem mesmo mediante a simples operação das forças "naturais" do mercado.

O projeto de industrialização foi sendo construído através de alianças políticas, regionais e de classe que atraíram os interesses mais retrógrados e reacionários para o bloco hegemônico. Na posteridade da Segunda Guerra Mundial, a expansão do internacionalismo capitalista comandada pelos EUA e a polarização da Guerra Fria colocaram novos 
desafios ao avanço da agenda desenvolvimentista. Quem se habituou a repetir, sem qualquer senso crítico, que o Brasil perseguiu um "modelo" autárquico, uma economia fechada, falsifica os fatos: a industrialização brasileira foi acompanhada de uma profunda internacionalização da estrutura produtiva econômica.

Ninguém está disposto a sustentar que tudo foi uma maravilha. A distribuição de renda é um desastre. Os níveis de pobreza são vergonhosos. A desproteção da população diante das incertezas da vida e das andanças da economia são constrangedoras. Pois foi à luz desta realidade - produzida pela resistência dos enclaves reacionários ao avanço social - que, nos anos 90, o cosmopolitismo liberal se lançou à aventura da desconstrução da idéia de nação. Para tanto se embrenhou nos misteres de ocultar e negar a existência de hierarquias e dominação nas relações internacionais, de exaltar as virtudes regeneradoras da concorrência, de estigmatizar a coordenação do Estado.

$\mathrm{Na}$ onda de louvação das virtudes do mundo globalizado e de exaltação do mercado, a rejeição ao "nacional" não só atingiu os níveis mais profundos das almas dos nativos ricos, mas também conseguiu angariar novos adeptos.

A nova rejeição é mais profunda porque, de forma devastadora, erodiu os sentimentos de pertinência à mesma comunidade de destino, suscitando processos subjetivos de diferenciação e (des)identificação em relação aos outros, ou seja, à massa de pobres e miseráveis que infesta o país. E essa (des)identificação vem assumindo cada vez mais as feições de um individualismo agressivo e anti-republicano.

A rejeição também foi mais ampla porque essas formas de consciência social contaminaram vastas camadas das classes médias: desde os "novos" proprietários, passando pelos quadros técnicos intermediários até chegar aos executivos assalariados e à nova intelectualidade formada em universidades estrangeiras ou mesmo em escolas locais que se esme- 
ram em reproduzir os valores do individualismo agressivo. Isto para não falar do papel avassalador da mídia.

Tais expectativas e anseios não são desvios psicológicos de grupos ou indivíduos, mas deitam raízes profundas na estrutura socioeconômica e, portanto, na secular inclinação a reproduzir a desigualdade. As classes cosmopolitas - sob a retórica de um "primeiro-mundismo" abstrato e, não raro, vulgar - têm sido eficientes na reprodução do apartheid social e impiedosas na crítica do projeto nacional. O cosmopolitismo das classes endinheiradas revela, ademais, o seu caráter parasitário, amparado na "dolarização" e na "financeirização" da riqueza e da renda dos estratos superiores, o que condena a economia aos suplícios de uma modernização restrita e intermitente, com seu séquito de destruição de empregos e exclusão social.

A dimensão individualista e anti-republicana destas formas de vida e de consciência, aliada à decadência eco64 nômica engendrada pelo rentismo periférico, deságua na anomia social e na impotência do Estado, cada vez mais inabilitado para o cumprimento de suas funções essenciais: garantir a segurança dos cidadãos e promover a universalização das políticas públicas de saúde, educação e previdência.

Muitos teimam em desconhecer que a liberdade moderna dos indivíduos movidos pela cobiça e pelo medo só sobreviverá se a força coercitiva e legal do Estado puder ser exercida em sua plenitude. Ao contrário do que imaginam, a sanção legal deve se apresentar claramente como uma ameaça iminente aos transgressores da lei. O não cumprimento dessa função é o primeiro passo para a reinstauração da guerra privada e, provavelmente, para o aparecimento de alguma forma de despotismo extralegal.

Aqui no Brasil estão presentes todos os sintomas de erosão da soberania do Estado. Além de despojado com requintes do monopólio da violência, o Estado brasileiro 
vem sendo atacado nas outras prerrogativas essenciais: a de cobrar impostos e a de administrar a moeda.

Não é nova a descoberta de que a abertura financeira e o endividamento em moeda estrangeira podem fazer mal à saúde das economias de moeda fraca. Mas, nas beiradas do mundo, os senhores não perdem a chance de fazer a América deglutir a carne macia e deixar os ossos para os gentios.

Os colunistas da moda e outros fora dela conseguiram bons empregos e até algum prestígio tentando afanosamente reproduzir as opiniões e os pontos de vista dos seus senhores, sejam eles quais forem, daqui ou de fora. Em algum momento, eles entoaram loas para as patranhas econômicas. Os que ainda têm reservas de pudor, para não alegar amnésia súbita, depois da derrocada parecem acometidos de uma modalidade bastante cômoda de esquizofrenia: dividiram racionalmente seus ressentimentos entre a fúria e a autocomplacência.

A fúria lançaram contra a política "incompetente e corrupta”, incorrigível no mister de fabricar consensos populistas e "de gastar acima de seus meios". A autocomplacência os sabichões reservaram, como sempre, para seus próprios erros, avaliações, aconselhamentos e previsões grotescas. Tudo pago em moeda forte.

Isso prova que Descartes foi generoso no Discurso do Método, quando imaginou imprudentemente que ninguém aspira mais 'bom senso' do que possui.

É verdade que o cogito não seria capaz de vislumbrar que de suas entranhas fosse expelida, no final do século XX, a Economics, este monstrum vel prodigium da metafísica ocidental, matraqueada nos tristes tópicos. O mau universalismo gera o péssimo particularismo como a banda podre de si mesmo. Na versão pós-moderna e globalizada, a dialética iluminista do universal e do particular se torna sofisticadamente cruel. Sua especialidade é o jogo do ilusionismo em que as subjetividades supostamente esclarecidas ou ilumi- 
nadas são reduzidas a meras objetivações de processos que não controlam.

A crise brasileira e, permita-me dizer, latino-americana, não é fruto da banalidade do mal, mas dos males da banalidade. Não se trata apenas da história de erros crassos e fundamentais de política econômica. Ela revela, em sua crueldade essencial, em sua desumanidade absoluta, até que ponto, no mundo contemporâneo, a pretensão do domínio das coisas e do controle dos processos sociais tornou-se, ao mesmo tempo, ilusória nos resultados e poderosa nos métodos.

É ilusória porque, quando entra em colapso a coordenação do mercado, o indivíduo - reduzido a um coágulo monetário e desamparado da reciprocidade solidária do grupo, da classe social, sobretudo das instituições republicanas - só dispõe da violência mimética que comanda os estágios primitivos da vida social.

66 É poderosa porque as normas impessoais da finança obstruem a ação da cidadania ao transmutar as ilusões em necessidades e as necessidades em ilusões.

Só o ronco surdo das ruas, a radicalização da democracia e de seus procedimentos será capaz de realizar o projeto moderno da garantia de uma vida boa e decente para a maioria. Reformas que regenerem a supremacia dos procedimentos políticos e administrativos constituídos à sombra do Estado moderno.

O Estado territorial, centralmente administrado, foi uma força estabilizadora no processo de desenvolvimento capitalista. "Esta formação", diz Habermas, "assegurou o quadro necessário para que o sistema capitalista se desenvolvesse à escala mundial. O Estado Nacional constitui a infra-estrutura necessária para a administração juridicamente disciplinada, garantindo ao mesmo tempo o espaço negativo de liberdade para a ação coletiva e individual... Estado Nacional e democracia nascem como criaturas gêmeas da Revolução Francesa.” 
O que está em jogo é o conflito entre os dois processos de universalização que se propagam desde o Iluminismo: a busca da igualdade entre os homens e os povos e a criação e acumulação da riqueza através da expansão mercantil.

Encerro com a utopia reformista radical de John Maynard Keynes, inscrita no pórtico da morada que o homem do século XX pretendeu construir:

"Estou à espera, em dias não muito remotos, da maior mudança que já ocorreu no âmbito material da vida, para os seres humanos no seu conjunto. Vejo-nos livres para voltar a alguns dos mais seguros e tradicionais princípios da religião e da virtude tradicional - de que a avareza é um vício, a usura uma contravenção, o amor ao dinheiro algo detestável... Valorizemos novamente os fins acima dos meios e preferiremos o bem ao útil. Honraremos os que nos ensinam a passar virtuosamente e bem a hora e o dia, as pessoas agradáveis capazes de ter um prazer direto nas coisas, os lírios do campo que não mourejam nem fiam.” (John Maynard Keynes - As Possibilidades Econômicas de Nossos Netos - 1930)

\section{Luiz Gonzaga Belluzzo}

é professor titular aposentado do Instituto de Economia da Unicamp 


\section{D)}

\section{ESPERANÇAS DO PASSADO}

\section{LUIZ GONZAGA BELLUZZO}

Com base no discurso em que foi agraciado com o Prêmio Juca Pato para "Intelectual do Ano" (2005), o autor faz um retrospecto da Economia e Política mundiais que, com os últimos dias da Segunda Guerra, deram ensejo, no plano internacional, a uma política progressista por parte das potências vitoriosas na luta contra o nazi-fascismo e, no Brasil, ao período desenvolvimentista. $\mathrm{O}$ retrospecto lhe permite fazer um contraste com as políticas ultraliberais que, em décadas mais recentes, ao mesmo tempo que interromperam aqueles experimentos de uma nova ordem internacional, passaram a lançar sombras sobre o futuro de países como o Brasil.

Palavras-chave: Economia e Política Internacionais do PósGuerra; Desenvolvimentismo no Brasil; Globalização; Estado Nacional.

\section{HOPES FROM THE PAST}

Based on his speech for the Juca Pato Award to "Intellectual of the Year" (2005), the author reviews the world Economy and Politics which, following the last days of the Second World War, have launched a progressive period in both the international arena 
and Brazil. The review is meant to call attention to the ultraliberal policies which, in more recent decades, have broken those experiments in a new international order at the same time that have shadowed the future of countries like Brazil.

Keywords: Post War International Economy and Politics; Developmentism in Brazil; Globalization; Nation-State. 